\title{
An Experimental Investigation on Partial Replacement of Cement with Rice Husk Ash and Fine Aggregate with Steel Slag
}

\author{
Insha Ali ${ }^{1}$, Dr. Esar Ahmad ${ }^{2}$ \\ ${ }^{1}$ Post Graduate Scholar, Civil Engineering Dept., Mewar University, Chittorgarh \\ ${ }^{2}$ Professor \& HOD, Civil Engineering Dept., Mewar University, Chittorgarh Rajasthan
}

\begin{abstract}
Concrete is the most normally utilized structure material for development and it expends nearly the all-out concrete substance creation on the planet. Rice husk debris gives great compressive solidarity to the solid. It is a side-effect; henceforth, it helps in chopping down the ecological contamination. The thickness of cement containing rice husk debris is like the ordinary weight concrete; consequently, it can likewise be utilized for the broadly useful application as well. The impenetrable microstructure of rice husk debris concrete gives better protection from the sulphate assault, chloride entrance, carbonation, and so forth. Rice Hush Ash concrete has great shrinkage property and expands the toughness of cement. Thusly this investigation of Rice Husk Ash based cement is useful and is more valuable for the future solid world. Steel slag is the sideeffect got from the steel business. It is created as a build-up during the creation of steel. Steel slag can be utilized in the development business as totals in concrete by supplanting totals. This prompts the decrease of landfills saved for its removal, sparing regular assets and accomplishing an expected situation. The possible use and ideal use of steel slag and Rice Husk Ash in the creation of cement. Examinations were completed on the adjustments in properties of solid when steel slag is utilized in concrete. Test results on compressive quality, split rigidity, flexural quality and functionality of cement uncovered that the quality of cement following 28 days expanded individually subsequent to supplanting sand by steel slag. After adjustment of steel slag properties by implanting it with Rice Husk Ash, the 28 days quality was seen to be expanded when contrasted with customary solid blend separately after substitution. Imbuing steel slag with Rice Husk Ash expanded the qualities of cement separately when contrasted with ordinary steel slag solid blend
\end{abstract}

Keywords: Steel Slag, Rice Husk Ash, Mix design, Compressive Strength, Tensile Strength.

\section{INTRODUCTION}

By and by a-days Concrete is the most comprehensively used improvement material. Strong accept basic occupation in the arrangement and advancement of nation's establishment. Almost of strong volume is made out of coarse aggregates which are gotten from typical rocks. In view of this the defilement of regular resources occurs. To fulfill the overall need of concrete later on, it transforms into an also inciting endeavor to find fitting alternatives as opposed to standard aggregates for preparing concrete. To beat the above said issue wastes made from elective sources are used. Steel slag is a mechanical reaction procured from the steel creating industry. It is conveyed in tremendous sums in steel making exercises which utilize Electric Arc Furnace (EAF) and can in like manner be set up by melting iron mineral in the Basic Oxygen Furnace slag (BOF). Steel slag made around reciprocals to the $20 \%$ by mass of steel yield. Steel slag can be used in the improvement business as all out in strong replacing normal sums. Various piece of our regular day to day existence depend really or in an indirect manner on concrete. Conventional concrete a versatile material is set up by mixing various constituents like solid, aggregate, water, etc. which are financially available. Concrete is unique among noteworthy advancement material since it is arranged unequivocally for explicit basic structure adventure. Strong accept an essential activity in the arrangement and advancement of the nation establishment. More than ten billion tons of concrete are exhausted yearly .Based on overall use it is set at second circumstance after water. All out substance is a factor, which has prompt and far - showing up at impacts on the idea of concrete.

\subsection{Rice Husk Ash}

Rice husk debris (RHA) fillers are gotten from rice husks, which are typically seen as agrarian waste and an environmental risk. Rice husk, when expended in outside the rice plant, yields two sorts of flotsam and jetsam that can fill in as fillers in plastics materials. The rice paddy preparing adventures give the outcome rice husk. As a result of the extending pace of environmental defilement and the idea of practicality factor have made utilizing rice husk. The clarifications for the use of rice husk as a possibility for concrete in strong gathering are explained in the going with zones. To have a fitting idea on the introduction of rice husk in concrete, a point by point concentrate on its properties must be finished. Around 100 million tons of rice paddy make reactions are gotten the world over. They have a low mass thickness of 90 to $150 \mathrm{~kg} / \mathrm{m} 3$. This results in a more vital estimation of dry volume. The rice husk itself has an unforgiving surface which is harsh in nature. These are therefore impenetrable to normal defilement. This would achieve unseemly expulsion issues. Among all dares to reuse this thing, cement, and strong gathering ventures are the ones who can use rice husk in a prevalent way. 


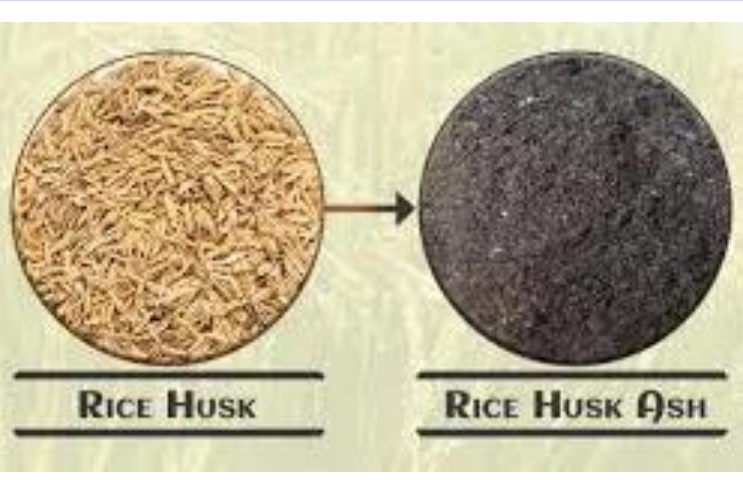

Figure 1: Rice Husk Ash

\subsubsection{Advantages of rice husk ash}

- Rice husk flotsam and jetsam invigorates extraordinary compressive.

- It is a reaction; along these lines, it helps in slashing down the natural defilement.

- The high silica content makes it a not too bad significant cementations material or pozzolanic admixture.

- The thickness of concrete containing rice husk flotsam and jetsam resembles the customary weight concrete; consequently, it can in like manner be used for the comprehensively valuable application too.

- The impervious microstructure of rice husk flotsam and jetsam solid gives better insurance from the sulfate attack, chloride passageway, and carbonation, etc.

- Rice body concrete has incredible shrinkage property and extends the strength of concrete.

\subsubsection{Disadvantages of rice husk ash}

- By the use of rise husk garbage, concrete progressively gets unworkable. In this manner water-diminishing admixtures should be used to get workable concrete for the effortlessness of circumstance and compaction of concrete.

\subsubsection{Applications}

- Unrivaled Concrete

- Green concrete

- Washroom floors

- Present day creation line floor materials

- Solidifying the foundation

- Pools

- Waterproofing and recoup

\subsection{Steel Slag}

An overall temperature change and common destruction has drawn closer as a noteworthy issue in the progressing years. Started upsetting in engineers mind, especially in basic pros mind. Scanning forward for finding the course of action of these issues and besides the usage of progressively more characteristic genial materials in every Industry particularly improvement industry is a central criticalness. Auxiliary fashioners start mulling over strong, which is progressively overall thing to be used by basic pros to make it environmental pleasant. Strong mix contains beneficial cementations material and admixtures which structures some segment of the cementations fragment. These materials are bigger part results from various methodology, out of all of these materials one of the accommodating reaction material is Steel slag.

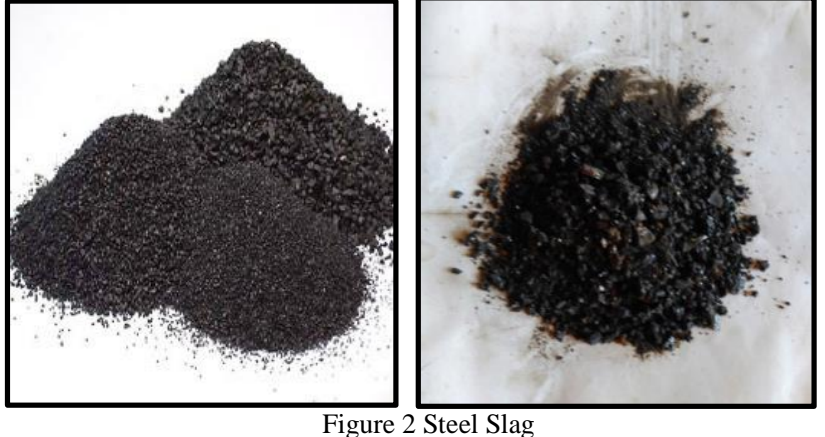

\section{LITERATURE REVIEW}

Muhammad Shoaib Ismail and A. M. Waliuddin : In this paper the High quality concrete (HSC) was conveyed using locally open material. The effect of rice husk garbage (RHA) going at $200 \mathrm{~mm}$ and $325 \mathrm{~mm}$ sifters as a $10-30 \%$ replacement of cement on the nature of HSC was also analyzed.

Min-Hong Zhang and V. Mohan Malhotra: This paper presents results on the physical and compound properties of rice husk garbage (RHA), and deals with the properties of new set concrete combining a comparable flotsam and jetsam.

Mr. Amitkumar I. Gupta, Dr. Abhay S.Wayal: In this paper Conventional structure material like cement is both resource and imperativeness concentrated material. Procduction of cement moreover communicates $\mathrm{CO} 2$ in atmosphere. In order to reduce this environmental sullying and cost of standard structure materials.

Tomas U. Ganiron. "Effects of rice husk as Substitute for fine absolute in strong mix". Jr College of Architecture, Qassim

University, Buraidah City. This examinations on the effect of rice husks as fine absolute to the extent water-solid extent, quality and size of coarse aggregate, and consistency of the mix and chooses how rice husk differ with other typical strong mix as fine all out similarly as water adsorption, compressive quality, unbending nature and modulus of adaptability.

Nithyambigai G ."Impact of Rice Husk Ash in Concrete as Cement and Fine Aggregate" Assistant Professor Department of Civil Engineering, SRM University, Ramapuram Chennai, Tamil Nadu.

Ashif $\mathbf{M}$ et al..Throughout the world, concrete is in effect extensively used for the improvement of an enormous segment of the structures, ranges, etc. In this way, it has been suitably named as the spine to the system improvement of a nation. Directly, our country is taking critical exercises to improve and develop its establishment by growing express roads, power adventures moreover, current structures to ascend as a huge money related power and it has been surveyed that the establishment divide in our country.

Mohd Rosli Hainin Samples were exposed to tough modulus test, creep test and rutting test. Steel slag show fundamentally preferable outcomes over traditional total. 
Karthini.K.This assessment investigates finding a replacement for cement to ensure legitimacy is indispensable as the unrefined material (limestone, stand, shale, earth, iron mineral) used in making cements which are ordinarily happening are depleting.

Deepa G Nair et al.This paper discusses the mechanical properties of RHA-High quality concrete at improved conditions. This will lessen the greatness of the finished endeavor, decay the cost, and dispose of the rice husk trash waste thing.

T. Subbulakshmi, et.al, Experiments were coordinated to examine mechanical properties of prevalent concrete with different rate replacement of mineral admixture and present day results, for instance, silica rage, base flotsam and jetsam and steel slag all out.

P.Sateesh Kumar, et.al. This paper intends to think probably, the effect of partial replacement of fine all out by steel slag (ss), on the diverse quality and durability properties of concrete by using the mix plans. the perfect degree of replacement of fine all out by steel slag is found.

\section{MATERIALS}

\section{Materials and Properties}

The constituent materials used in this study are given below:

\subsection{Cement}

The cement used was ordinary Portland cement of 53-grade in accordance with IS: 12269-1987. The cement should be fresh and of uniform consistency. The cement should be stored under dry conditions and for as short duration as possible.

Table 1: Properties of cement

\begin{tabular}{|l|l|l|}
\hline S. No & Property & Test Result \\
\hline 1 & Grade of cement & 53 \\
2 & Specific gravity & 3.15 \\
3 & Normal consistency & $30 \%$ \\
4 & Initial setting time & $45 \mathrm{~min}$ \\
5 & Fineness of cement & $3 \%$ \\
\hline
\end{tabular}

\subsection{Fine Aggregate}

The sand passing through $4.75 \mathrm{~mm}$ sieve and retained on $600 \mu \mathrm{m}$ sieve, conforming to Zone III as per IS 383-1970 was used as fine aggregate in the present day. The sand is free from clay, silt and organic impurities. The aggregate was tested for its physical requirements such as gradation, fineness modulus, and specific gravity and bulk modulus in accordance with IS: 2386-1963. Sieve analysis is carried out and the results are shown

Table 2. Properties of Fine Aggregates

\begin{tabular}{|l|l|l|}
\hline S. No. & Property & Test Result \\
\hline 1 & Specific gravity & 2.56 \\
\hline 2 & Bulk density $\left(\mathrm{kg} / \mathrm{m}^{3}\right)$ & 1714.58 \\
\hline 3 & Fineness Modulus & 2.94 \\
\hline 4 & Zone & III \\
\hline
\end{tabular}

\subsection{Coarse Aggregates}

Throughout the investigations, a machine crushed angular granite metal of $20 \mathrm{~mm}$ nominal size from the local source is used as coarse aggregate. It is free from impurities such as dust, clay particles and organic matter etc. The coarse aggregate is also tested for its various properties.

Table 3. Properties of Coarse Aggregates

\begin{tabular}{|c|c|c|}
\hline S. No & Property & Test Result \\
\hline 1 & Specific Gravity & 2.68 \\
\hline 2 & Bulk Density $\left(\mathrm{Kg} / \mathrm{m}^{3}\right)$ & 1720.69 \\
\hline 3 & Fineness Modulus & 7.55 \\
\hline
\end{tabular}

\subsection{Water}

Water is an important ingredient of concrete as it actively participates in the chemical reaction with cement. Since it helps to form the strength giving cement gel, the quantity and quality of water is required to be looked into very carefully. Mixing water should not contain undesirable organic substances or inorganic constituents in excessive proportions. Analysis of water (Limitations as per IS: 456-2000)

\subsection{Rice Husk Ash}

Rice Husk Ash is an agricultural waste obtained from milling of rice. This is usually being thrown away to the landfill without further use, thus contribute to environmental pollution. Rice Husk Ash is a by-product from the burning of Rice Husk under controlled temperature and burning time. In the present investigation Rice Husk Ash was partially replaced in Portland cement at various percentages to study compressive strengths and split tensile strengths. The physical properties and chemical composition of Rice Husk Ash

Table 4. Physical Properties of Rice Husk Ash.

\begin{tabular}{|l|l|l|}
\hline S. No. & Property & Test Result \\
\hline 1 & Density & $495 \mathrm{~kg} / \mathrm{m}^{3}$ \\
\hline 2 & Specific Gravity & 2.53 \\
\hline 3 & Mean particle size & $0.15-0.25 \mu \mathrm{m}$ \\
\hline 4 & Colour & Grey \\
\hline 5 & Min specific surface area & $220 \mathrm{~m}^{2} / \mathrm{kg}$ \\
\hline 6 & Particle shape & Spherical \\
\hline 7 & Moisture contents (\% by weights) & 2.15 \\
\hline
\end{tabular}

\subsection{Steel Slag}

Slag is a by-product generated during manufacturing of pig iron and steel. Primarily, the slag consists of calcium, magnesium, manganese and aluminium silicates in various combinations. The slag is generated by the addition of fluxes, such as lime stone and dolomite that combine with silicates and oxides to form liquid slag. Basic oxygen furnace slag has increased skid resistance and high level of strength described by the impact- and crushing value compared to natural rocks and thus makes it an ideal aggregate for road constructions and surface layers for high skid resistance. 
Table 5. Physical Properties of Steel Slag

\begin{tabular}{|l|l|l|}
\hline S No. & Designation & Properties \\
\hline 1 & Colour & Light to dark brown \\
\hline 2 & Shape & Highly angular \\
\hline 3 & Bulk density & $1911.11 \mathrm{~kg} / \mathrm{m} 3$ \\
\hline 4 & $\mathrm{pH}$ (in water) & 8 \\
\hline 5 & Combustibility & Non-combustible \\
\hline 6 & Surface Texture & Rough \\
\hline 7 & Specific gravity & 2.93 \\
\hline
\end{tabular}

\subsection{Compressive Strength}

The compression test is carried out on specimens cubical or cylindrical in shape. Prism is also sometimes used, but it is not common in our country. The end parts of the beam are left intact after failure in flexure and, because the beam is usually of square cross section, this part of the beam could be used to find out the compressive strength.

Compressive Strength $=$ P/A

\subsection{Split Tensile Strength}

Split Tensile strength is obtained by applying crushing load on the cylinder surface. Split Tensile strength of concrete is calculated by casting $150 \mathrm{~mm}$ diameter and $300 \mathrm{~mm}$ cylinders. The test results are presented here for the split tensile strength of 7, 14 days and 28 days of testing.

\subsection{Flexural Strength}

Flexural test was performed on beams size of $500 \mathrm{~mm} \times$ $100 \mathrm{~mm} \times 100 \mathrm{~mm}$ size by placing them on universal testing machine find out the flexural strength.

\subsection{Mix Proportions}

Table 6. Table of Mix Proportions

\begin{tabular}{|c|c|c|}
\hline S.NO & MIXES ID & PROPORTIONS \\
\hline 1 & MIX-1 & 0\% Rice Husk Ash \& 0\% Steel Slag \\
\hline 2 & MIX-2 & $5 \%$ Rice Husk Ash \& 5\% Steel Slag \\
\hline 3 & MIX-3 & $\begin{array}{c}10 \% \text { Rice Husk Ash \& 10\% Steel } \\
\text { Slag }\end{array}$ \\
\hline 4 & MIX-4 & $\begin{array}{c}15 \% \text { Rice Husk Ash \& 15\% Steel } \\
\text { Slag }\end{array}$ \\
\hline 5 & MIX-1 & $\begin{array}{c}20 \% \text { Rice Husk Ash \& 20\% Steel } \\
\text { Slag }\end{array}$ \\
\hline
\end{tabular}

\subsection{Compression Strength}

4. RESULTS AND DISCUSSIONS

\begin{tabular}{|l|l|l|l|}
\hline Mix Id & 7 Days & 14 Days & 28 Days \\
\hline Mix-1 & 26.50 & 36.13 & 40.15 \\
\hline Mix-2 & 29.04 & 39.60 & 44.00 \\
\hline Mix-3 & 32.85 & 44.80 & 49.78 \\
\hline Mix-4 & 32.85 & 39.87 & 39.87 \\
\hline Mix-5 & 28.16 & 38.40 & 38.40 \\
\hline
\end{tabular}

\section{Compression Strength}

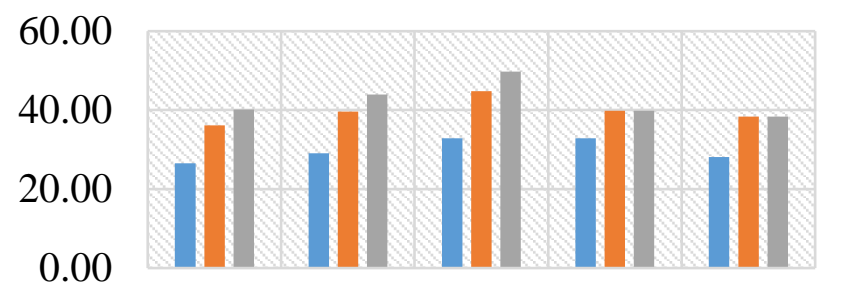

Mix-1 Mix-2 Mix-3 Mix-4 Mix-5

7 Days $\quad 14$ Days $\quad 28$ Days

\subsection{Split Tensile Strength}

\begin{tabular}{|l|l|l|l|}
\hline & 7 Days & 14 Days & 28 Days \\
\hline Mix-1 & 2.75 & 3.46 & 4.44 \\
\hline Mix-2 & 2.81 & 3.53 & 4.53 \\
\hline Mix-3 & 2.85 & 3.59 & 4.60 \\
\hline Mix-4 & 2.85 & 3.31 & 3.31 \\
\hline Mix-5 & 2.57 & 3.24 & 3.24 \\
\hline
\end{tabular}

\section{Split Tensile Strength}

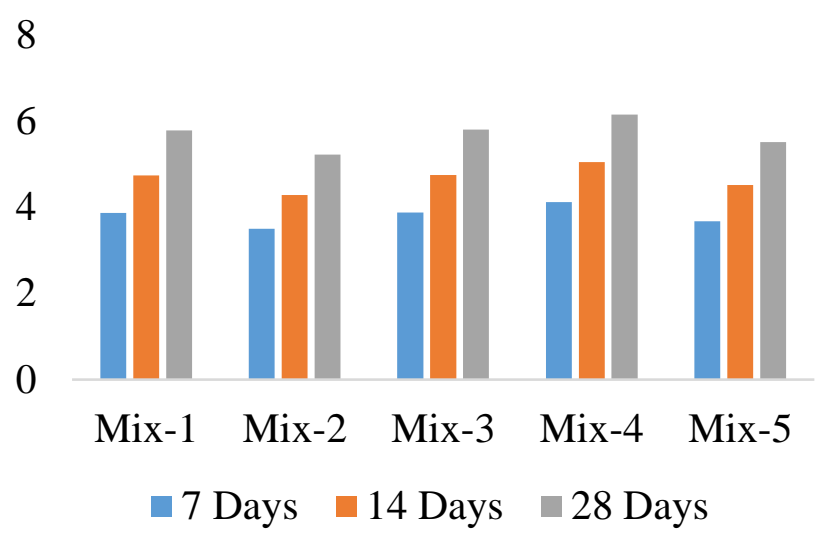

\subsection{Flexural Strength}

\begin{tabular}{|l|l|l|l|}
\hline & 7 Days & 14 Days & 28 Days \\
\hline Mix-1 & 3.87 & 4.74 & 5.78 \\
\hline Mix-2 & 3.50 & 4.28 & 5.22 \\
\hline Mix-3 & 3.88 & 4.75 & 5.80 \\
\hline Mix-4 & 4.12 & 5.05 & 6.15 \\
\hline Mix-5 & 3.67 & 4.52 & 5.51 \\
\hline
\end{tabular}

\section{Flexural Strength}

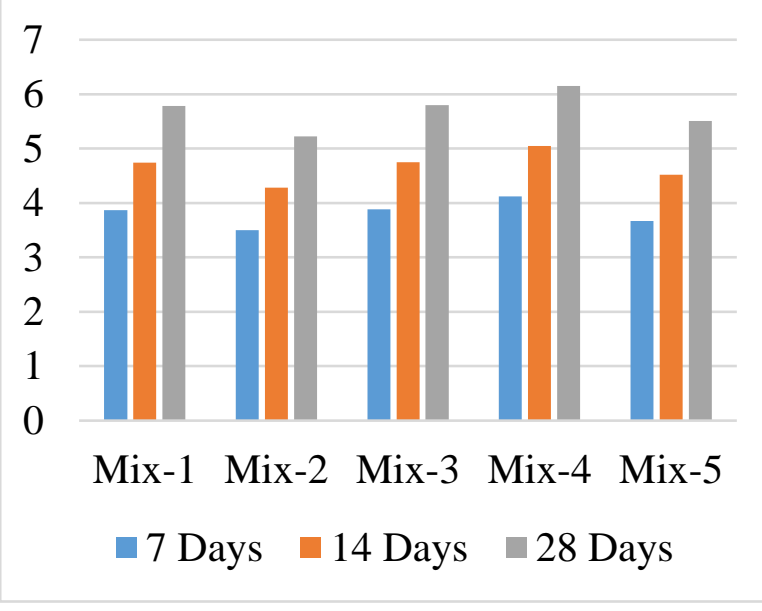

\section{CONCLUSIONS}

- The present investigation was to find the effectiveness of materials such as Rice Husk Ash and steel slag partial replacement in concrete. Experimental study was carried out to find the parameter such as strength, durability of concrete.

- Using nanomaterial such as Nano-silica in concrete improves the hardened properties, durability characteristics and reduces the workability which can be adjusted by adding the super plasticizer. Thus, by using 
nanotechnology in the construction industry can produce high-performance concrete for the future engineering structures.

- The slight improvement in strength may be due to shape, size and surface texture of steel slag aggregates, which provide better adhesion between the particles and cement matrix.

- The partial replacement of cement with Rice Husk Ash and Natural aggregates with steel slag aggregates permits a gain of compressive, tensile and flexural strength and durability of concrete upto an optimum value of replacement.

- Another important parameter to be included in the design mix is the determination of specific gravities of materials, as they may affect the yield of the concrete, which involves huge quantity of concrete.

- The results obtained from $7^{\text {th }}$ day, $14^{\text {th }}$ day $\& 28^{\text {th }}$ day compressive, tensile and flexural strength tests prove that the concrete attains high initial and final strength compared to the conventional concrete. The percentage increase in strength of concrete after 28 days was found out to be increased.

- Indian standard codes of practice must be introduced for testing materials, mixing design, durability of concrete and strength of concrete particles.

\section{REFERENCES}

[1] IS:2386-1963 (Part-III). Methods of Test for aggregates for concrete Part III specific gravity, density, voids, absorption and bulking. Bureau of Indian Standard, New Delhi-1963.

[2] IS:383-1970. Specification for coarse aggregate and fine aggregate from natural sources for concrete. Burea of Indian Standards.

[3] IS:455-1989. Portland Slag Cement- Specification. Burea of Indian Standards.

[4] IS:456-2000. Plain and Reinforced concrete- code of practice (Fourth Revision). Bureau of Indian Standards.

[5] IS: 383-1970: Specification for Coarse and Fine Aggregates New Delhi1963.from Natural Sources for Concrete, Bureau of Indian Standard,New Delhi-1970.

[6] IS: 10262-1982: Recommended guidelines for concrete mix design, Bureau of Indian Standard, New Delhi-2004.

[7] Givi, A. N. and Rashid, S. A. (2011). The effect of lime solution on the properties of $\mathrm{SiO} 2$ nanoparticles binary blended concrete. Composites (Part B) Vol. 42, 562-569.

[8] A.M. Said, M.S. Zeidan, M.T. Bassuomi and Y. Tian. (2012). Properties of concrete incorporating nano-silica. Construction and Building Materials 36, 838-844.

[9] Mukharjee, Bibhuti Bhusan, Barai and Sudhirkumar V. (2014). Influence of incorporation of nano-silica and recycled aggregates on compressive strength and microstructure of concrete. Construction and Building Materials 71, 570-578.

[10] Khajuria Chetan, Rafat Siddique, "Use of Steel Slag as Partial Replacement of Sand to Concrete", International Journal of Science, Engineering and Technology Research (IJSETR), Volume 3, Issue 6, June 2014 1877ISSN: 2278 - 7798, pp 1877-1880. 